\title{
ANALISIS KESIAPAN PETANI SWADAYA DALAM MENGHADAPI RANCANGAN PERATURAN PRESIDEN NO. 44 TAHUN 2020 TENTANG PENGELOLAAN KELAPA SAWIT BERKELANJUTAN DITINJAU DARI ASPEK STATUS LAHAN, LEGALITAS DAN SUMBER BIBIT DI KABUPATEN INDRAGIRI HILIR
}

\author{
Mulono Apriyanto ${ }^{1}$, Muhammad Arpah ${ }^{2}$, Amd. Junaidi $^{3}$ \\ ${ }^{1}$ Program Studi Teknologi Pangan \\ ${ }^{2}$ Program Studi Agroteknologi \\ ${ }^{3}$ Program Studi Agribisnis \\ Fakultas Pertanian, Universitas Islam Indragiri
}

mulonoapriyanto71@gmail.com

\begin{abstract}
Abstrak
Salah satu upaya yang saat ini dilakukan oleh pemerintah Indonesia untuk memastikan keberlanjutan pengembangan industri kelapa sawit adalah menciptakan standar keberlanjutan yang disebut Indonesian Sustainable Palm Oil (ISPO) dalam peraturan presiden no 44 tahun 2020. Tujuan dari penelitian ini adalah untuk menentukan nilai kemampuan petani swadaya kelapa sawit di Indragiri Hilir untuk memenuhi standar Indonesia Sustainable Palm Oil (ISPO) dan mengidentifikasi masalah yang dihadapi dalam mencapai standar-standar ini. Evaluasi kemampuan petani swadaya untuk mencapai standar ISPO dilakukan dengan metode audit, hasil penilaian dari semua parameter yang ditetapkan sesuai dengan Prinsip, Kreteria dan Indaktor. Kriteria dan Indikator yang terkandung dalam ketentuan ISPO kemudian dinilai dalam satuan persen. Metode audit dilakukan secara analisis deskriptif kuantitatif kesesuaian antara prinsip, kriteria dan indikator ISPO dengan membandingkan pelaksanaan legalitas, organisasi dan pengelolaan, pengelolaan dan pemantauan lingkungan yang diterapkan oleh petani swadaya. Kesiapan penerapan ISPO pada petani sawdaya dengan melakukan penilaian terhadap empat prinsip, 20 kriteria dan 47 indikator. Dari 47 indikator yang ditetapkan pada persayaratan ISPO pola swadaya, sebanyak $58,94 \%$ indikator ISPO belum pernah dijalankan petani swadaya dan sebesar 42,06 \% indikator ISPO sudah ada petani yang menjalananya. Dari indikator ISPO yang sudah dijalankan petani swadaya, hanya dijalankan oleh sebahagian kecil petani swadaya.
\end{abstract}

Kata Kunci : ISPO, Kelapa Sawit, Swadaya.

\section{PENDAHULUAN}

Subsektor perkebunan di Indonesia telah menjadi salah satu sumber devisa non-migas dan mampu menyediakan lapangan kerja bagi lebih dari 6 juta orang (Risa, 2018). Kelapa sawit merupakan komoditas pilihan dalam program revitalisasi perkebunan berdasarkan beberapa pertimbangan, di antaranya: (1) komoditas yang 
dikembangkan memiliki peran yang sangat strategis sebagai sumber pendapatan masyarakat, (2) komoditas yang dikembangkan memiliki prospek pasar, baik dalam pasar domestik dan ekspor (Puspa, 2018). Perkebunan kelapa sawit di Indonesia pada 2012 mencapai 9,5 juta hektar, Pada 2017 produksi CPO Indonesia naik dari 23,5 juta ton menjadi 26 juta ton atau tumbuh $11,01 \%$, dengan jumlah produksi Indonesia masih merupakan produsen minyak sawit terbesar dan menguasai $48 \%$ dari total pangsa pasar dunia (Irianto dan Mulono Apriyanto 2012), (Apriyanto Mulono et al. 2017), (Anonim 2020).

Jumlah produksi perkebunan sawit di Indonesia pada tahun 2016 adalah 33,23 juta ton, yang dihasilkan dari 11,91 juta Ha luas total areal perkebunan kelapa sawit secara nasional. Secara proporsional, 54,64 persen kebun sawit nasional diusahakan oleh perusahaan besar swasta (PBS). Sisanya, sekitar 39,08 persen diusahakan oleh rakyat (termasuk plasma) dan sebagian kecil diusahakan oleh perkebunan besar milik negara (PBN) (Ditjen Perkebunan, 20152017).

Di Indonesia ada tiga pola pengelolaan perkebunan kelapa sawit yaitu perusahaan, plasma dan swadaya. Swadaya adalah pola pengembangan perkebunan kelapa sawit yang dilakukan oleh petani sendiri, mulai dari pembukaan lahan, penanaman, pemeliharaan, panen pemasaran hasil tanpa melalui kemitraan usaha. Pola pengelolaan swadaya merupakan luas lahan yang paling luas dari tiga pengelolaan kebun kelapa sawit yang ada di Indonesia, dan kebun pola swadaya ini mengalami peningkaatan terus. Peningkatan luas lahan pola swadaya tidak seimbang dengan peningkatan produktivitasnya, dimana produktivitas pola swadaya lebih rendah dari perusahaan besar, produktivitas pola swadaya hanya sekitar 2,5 sampai 3 ton per hektar, sedang perkebunan besar swasta sekitar 3,5 sampai 4 ton per hektar. Provinsi Riau dan Sumatera Utara merupakan provinsi sentra produksi CPO terbesar di Indonesia dengan kontribusi masing-masing sebesar 23,75 persen dan 16,24 persen (Kementerian Pertanian, 2016). Ekspansi lahan perkebunan sawit adalah katakunci yang penting untuk mulai memahami semesta persoalan kelapa sawit di Indonesia.

Ekspansi tersebut telah dianggap bertanggungjawab atas terjadinya penggundulan hutan (deforestasi), emisi karbon, dan hilangnya keanekaragaman hayati (Puspa 2018), (Anwar et al. 2016). Selaras dengan hal itu, muncul tudingan yang meluas bahwa industri minyak kelapa sawit sebagai tidak berkelanjutan (unsustainable). Di balik pencapaian keberhasilan yang ada, industri perkebunan kelapa sawit Indonesia juga dihadapkan pada tantangan yang harus diatasi dengan bijaksana, yaitu pandangan kuat yang menggambarkan bahwa pengembangan perkebunan kelapa sawit Indonesia berdampak pada kerusakan sumber daya alam dan kelestarian lingkungan. Kampanye negatif, baik di dalam negeri maupun di luar negeri semakin ketat, tuntutan yang sering dilontarkan di antara para pemangku kepentingan adalah bahwa pengembangan kelapa sawit di Indonesia menerapkan sistem pengembangan kelapa sawit berkelanjutan. Salah satu upaya yang dilakukan oleh pemerintah Indonesia untuk memastikan keberlanjutan pengembangan industri kelapa sawit adalah menciptakan standar keberlanjutan kebun yang disebut The 
Indonesian Sustainable Palm Oil (ISPO) (Anonim 2020).

Pemerintah Indonesia melalui Kementerian Pertanian, meredam tudingan negatif tersebut dengan memberikan sertifikat Indonesia Sustainable Palm Oil (ISPO) kepada usaha /pelaku kelapa sawit di Indonesia, ISPO pada tahun 2012 secara resmi dikeluarkan oleh Direktorat Jenderal Perkebunan, standar ini sudah berlaku dan wajib karena ISPO didasarkan pada hukum dan peraturan pemerintah Indonesia. ISPO adalah pedoman dan juga komitmen berdasarkan hukum dan peraturan yang berlaku di Indonesia. Ketentuan ini wajib atau harus diterapkan untuk pelaku usaha perkebunan di Indonesia dan target penerapannya setelah keluar peraturan presiden (perpres) (Anonim 2020). ISPO bersifat mandatory atau wajib dan akan ada sanksi bagi perusahaan dan petani swadaya yang tidak melakukan/memiliki sertifikasi ISPO.

Kabupaten Indragiri Hilir sama halnya dengan kondisi di Indonesia umumnya, dimana juga terdapat 3 pola pengelolaan kebun kelapa sawit. Luas lahan pengelolaan pola swadaya, juga merupakan yang terluas dari dua pola lainnya. Kondisi geografis Indragiri hilir yang terdiri dari daaerah dengan tipologi daratan, pasang surut dan pesisir, dimana luas lahan yang besar adalah yang bertipologi rawa (pasang surut) dan pesisir. Kondisi tipologi daerah Inhil ini menyebabkan produktivitas yang rendah, kualitas buah yang rendah, letak kebun yang terpencar dengan sarana jalan yang rusak dan biaya angkut yang tinggi serta rantai pemasaran yang panjang menjadikan harga jual TBS yang diterima petani swadaya jauh lebih rendah dibanding petani pola PIR. Memperhatikan masalah ini, perlu dilakukan penelitian untuk menentukan nilai kesiapan petani swadaya kelapa sawit di Kabupaten Indragiri Hilir untuk memenuhi standar Minyak Sawit Berkelanjutan Indonesia (ISPO) dan masalah apa yang dihadapi petani swadaya dalam memenuhi standarstandar ini (Apriyanto Mulono et al. 2017), (Apriyanto et al. 2017), (Dharmawan et al. 2019).

Berdasarkan uraian diatas penelitian bertujuan untuk mengidentifikasi dan menganalisis penerapan ISPO ditingkat petani swadaya di Indragiri Hilir.

\section{METODE PENELITIAN}

Studi ini dilakukan pada sentra perkebunan kelapa sawit rakyat (smallholders) di tiga desa di wilayah Kabupaten Indragiri Hilir, yaitu desa Kempas Jaya, desa Teluk lanjut dan desa pelangiran. Lokasi studi ditetapkan secara sengaja, dengan pertimbangan bahwa ketiga lokasi tersebut termasuk dalam kelompok (cluster) lima besar sentra perkebunan kelapa sawit di Kabupaten Indragiri Hilir. Luas perkebunan kelapa sawit swadaya menjadi penting untuk dipertimbangkan sebagai parameter studi karena studi ini bertujuan untuk mengukur seberapa besar kesiapan petani kelapa sawit swadaya menghadapi kebijakan Indonesian Sustainable Palm Oil (ISPO). Studi ini berfokus pada smallholders, mengingat jumlahnya yang sangat substansial dan melakukan ekspansi yang cukup cepat secara sporadik dan hampir tidak terkendali karena skalanya yang kecil tetapi menyebar.

Ketiga desa yang dipilih sebagai kasus dalam studi ini diharapkan mewakili desa-desa dengan rumah tangga petani sawit swadaya yang memiliki kompleksitas persoalan pada aspek legalitas lahan, bibit dan pengelolaan lingkungan hidup serta struktur nafkah yang khas. Ketiga desa 
ini secara faktual berada pada kawasan lahan gambut dan berbatasan dengan perusahaan perkebunan swasta besar di wilayah Kabupaten Indrgiri Hilir. Fakta lapangan memperlihatkan bahwa beberapa bagian dari kebun kelapa sawit milik rumahtangga petani berada di dalam kawasan hutan yang secara hukum agraria dinyatakan ilegal. Penetrasi perkebunan kelapa sawit ke dalam kawasan hutan menjadi tantangan besar isu keberlanjutan produksi kelapa sawit, utamanya terkait dengan aktivitas deforestasi (Schouten and Glasbergen., 2011; Wicke et al. 2011; Hansen et al. 2015) dan alih fungsi lahan serta perubahan lanskap ekologi kawasan (Wicke et al. 2011; Gatto et al.,2015; Hansen et al. 2015; Euler et al. 2017) yang mengkhawatirkan.

Data yang dikumpulkan meliputi data primer dan data sekunder. Data primer dikumpulkan melalui metode survai dengan menggunakan kuesioner dan wawancara mendalam (indepth interview) dengan menggunakan pedoman wawancara. Pengambilan sampel untuk metode survei dilakukan terhadap rumah tangga petani kelapa sawit yang sudah melakukan budidaya kelapa sawit minimal lima tahun (telah menghasilkan) dan sudah panen minimal satu kali panen. Pemilihan responden dipilih secara acak sederhana yaitu sebanyak 30 responden untuk tiap desa dengan asumsi jumlah ini sudah memenuhi jumlah minimum responden yang harus disurvey yang dihasilkan oleh perhitungan dengan rumus Slovin, dengan margin of error sebesar $20 \%$. Kerangka sampling dari studi ini adalah rumah tangga petani yang kebunnya berada dan tinggal di desa tersebut. Sampel rumahtangga petani diambil secara acak sederhana, dimana setiap rumah tangga mempunyai kesempatan yang sama untuk dipilih sebagai sampel
(Nugraheni dan Pangaribuan 2008). Sementara data sekunder diambil dari berbagai referensi yang relevan.

Analisis data penelitian ini meliputi: 1) struktur nafkah di tiga desa untuk melihat apakah pendapatan yang berasal dari perkebunan kelapa sawit mencukupi dalam mendukung dalam program sertifikasi ISPO; 2) analisis tentang legalitas meliputi tiga aspek legalitas yang dipersyaratkan yaitu legalitas lahan, bibit, dan lingkungan; dan 3) melihat bagaimana (kemungkinan) implementability dan operasionalisasi sertifikasi ISPO pada petani kelapa sawit swadaya atau smallholders di tiga desa penelitian. Pada dasarnya terdapat tujuh prinsip penilaian ISPO, namun dalam penelitian ini hanya dibatasi pada ruang lingkup implementasi prinsip ISPO yang berlaku bagi smallholders saja yaitu aspek livelihood legalitas lahan, bibit, dan lingkungan hidup. Pelaksanaan penelitian ini dari bulan November 2018 sampai dengan Maret 2019.

\section{HASIL DAN PEMBAHASAN}

\section{Nafkah Petani Swadaya Kelapa Sawit}

Dugaan awal penelitian ini adalah semakin dominan sumber nafkah dari sektor perkebunan kelapa sawit di dalam struktur nafkah rumahtangga petani, maka kesiapan rumahtangga petani sawit untuk mengimplementasikan sertifikasi ISPO akan semakin baik. Fakta dilapangan menunjukkan jarang rumah tangga petani swadaya yang struktur nafkahnya hanya menggandalkan semata mata didukung sumber tunggal hasil kebun kelapa sawit.

(Sibarani et al., 2015) dan (Abdullah et al. 2019) menjelaskan bahwa dalam upaya mempertahankan hidup, menekan krisis dan sambil tetap mempertahankan kesejahteraan rumah 
tangga petani swadaya melakukan divesifikasi nafkah. Adanya diversifikasi ini menunjukan dominasi hasil kelapa sawit yang menjadikan dorongan petani swadaya untuk melaksanakan sertifikasi. Dalam negara berkembang sumber nafkah petani dipedesaan terdiri dari 3 sumber nafkah yaitu : farm income, off farm income, dan non farm income yang dimanfaatkan sedemikian rupa untuk mempertahankan eksistensi kehidupannya serta merespon tekanan atau perubahan dari kondisi sekitar (Euler et al. 2017;
Dharmawan et al. 2019; Mulyo et al., 2015). Guna mempermudah dalam mengklasifikasikan dalam penelitian ini tetapi akan disederhanakan menjadi tiga sumber yaitu perkebunan kelapa sawit (oil palm), petanian secara umum (agriculture), dan non farm activities (semua aktivitas nafkah di luar sektor pertanian). Hasil menunjukan bahwa struktur nafkah di tiga desa sebagaimana tersaji pada Gambar 1.

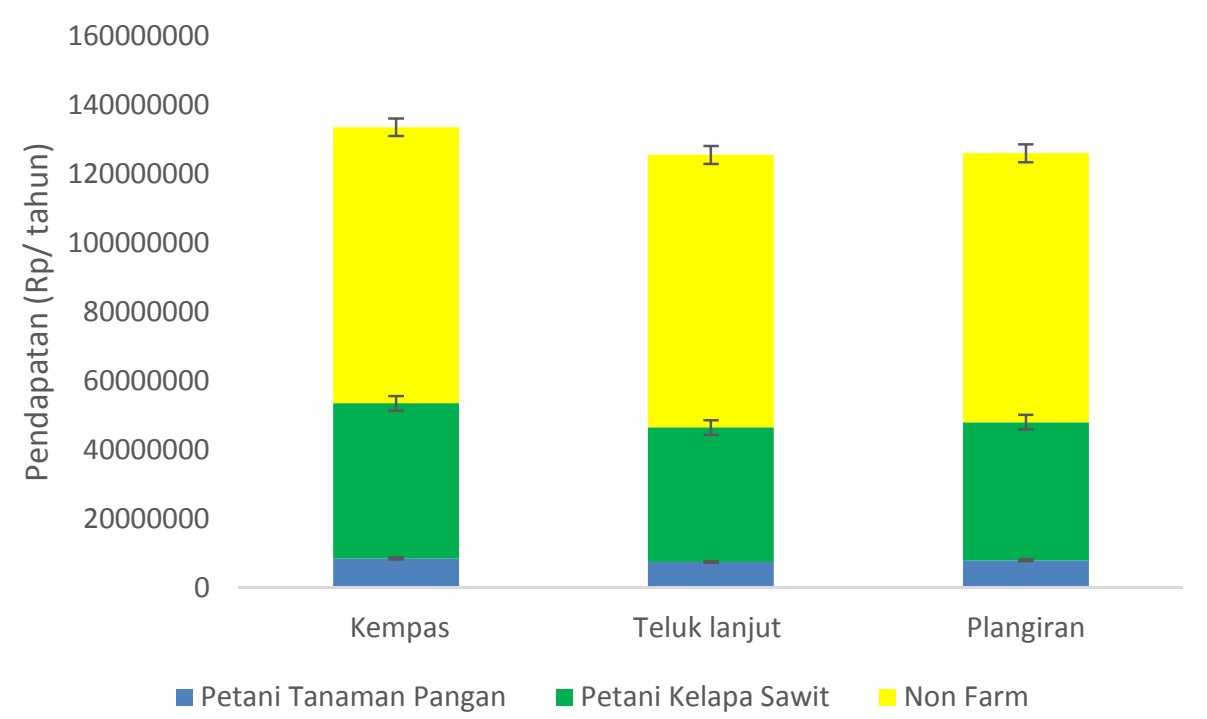

Gambar 1. Sruktur Nafkah Rumah Tangga Petani Swadaya di Desa Kempas Jaya, Desa Teluk Lanjut dan Desa Plangiran. (sumber data penelitian).

Dari Gambar 1 terlihat bahwa struktur nafkah petani swadaya ditiga desa bukan kelapa sawit bukan merupakan pendapatan yang dominan. Gambar 1 menunjukkan bahwa sesungguhnya sumber nafkah dari perkebunan kelapa sawit tidak cukup signifikan untuk mengatakan bahwa tiga desa tersebut adalah sentra perkebunan sawit rakyat secara ekonomi, dimana sertifikasi ISPO dapat dengan mudah diimplementasikan.

Struktur nafkah yang tidak didominasi oleh pendapatan dari kelapa sawit, maka sertifikasi ISPO dapat diterapkan kepada rumah tangga petani kelapa sawit swadaya, maka biaya sertifikasi justru akan membebani sumber nafkah lainnya. Hal ini disebabkan karena proses sertifikasi ISPO membutuhkan biaya yang cukup signifikan bagi smallholders, sementara sesungguhnya struktur nafkah rumah tangga petani kelapa sawit di banyak sentra produksi masih lemah.

Apabila rumah tangga petani kelapa sawit swadaya ingin memperbesar kontribusi ekonomi dari kelapa sawit, satu-satunya jalan yang dapat ditempuh oleh rumah tangga 
petani kelapa sawit swadaya adalah dengan melakukan ekspansi lahan (sesuatu yang akan menghasilkan resiko lingkungan hidup sangat serius).

Dua keadaan ini akan terlihat dua hal : (1) kemungkinan smallholders tidak bergairah untuk mengimplementasikan ISPO karena proporsi nafkah dari kelapa sawit yang rendah; (2) Akan terjadi banyak lahan yang tereksklusi dari sertifikasi ISPO karena dipandang illegal. Tujuan ISPO sebenarnya yaitu mengeluarkan lahan illegal dari sistem produksi legal dan berkelanjutan,agar kredibilitas pasar CPO di mata internasional dapat meningkat pada akhirnya.Resiko ini tentu berat bagi petani, oleh karenanya harus ada langkah opsional bagi peningkatan kesejahteraan.

Guna menyelesaikan kendala di tingkat petani swadaya maka peningkatan produktivitas dapat berimplikasi pada peningkatan kontribusiekonomi dari kelapa sawit dalam struktur nafkah. Artinya, kesiapan rumah tangga petani kelapa sawitswadaya dalam melakukan sertifikasi ISPO dapat ditingkatkan hanya jika rumah tangga petani kelapa sawit swadaya mampu meningkatkan produktivitas per hektar lahan kelapa sawit yang mereka miliki, sehingga tingkat pendapatan rumah tangga meningkat. Tetapi faktor eksternal berupa peningkatan ataupun penurunan harga kelapa sawit dunia tetap harus menjadi perhatian, karena berpotensi menambah atau mengurangi kontribusi pendapatan rumah tangga yang berasal dari sektor kelapa sawit terhadap keseluruhan pendapatan rumah tangga.

Berdasarkan struktur nafkah rumah tangga petani kelapa sawit swadaya di tiga desa lokasi penelitian dapat disimpulkan bahwa kondisi struktur nafkah rumahtangga petani kelapa sawit swadaya saat ini sejatinya belum siap untuk dilakukannya proses sertifikasi ISPO, kecuali perbaikan mendasar pada aspek produktivitas dilakukan terlebih dahulu, kredibilitas CPO Indonesia di pasar internasional, tetap rendah atau gloomy sepanjang struktur nafkah sebagaimana dijelaskan di atas, terus berlangsung.

\section{Legalitas Lahan Budidaya}

Salah satu prinsip yang harus dipenuhi menuju ISPO adalah legalitas lahan yang dibuktikan dengan kepemilikan sertifikat tanah, akta jual beli tanah, dan bukti kepemilikan tanah lainnya yang sah. Seperti tertuang dalam Keputusan Menteri Pertanian Indonesia No. 19/Permentan/OT.140/3/2011. Secara ideal, skema sertifikasi ISPO merencanakan agar seluruh petani kelapa sawit swadaya di Indonesia dapat tersertifikasi (Brandi et al. 2013) (Takrama et al. 2015).

Sertifikasi ISPO, akan melihat tentang penggunaan lahan untuk kebun sawit di Indonesia terutama bagi petani kelapa sawit swadaya. Studi kelak menyimpulkan bahwa tidak semua lahan petani bisa diikutsertakan dalam sertifikasi ISPO, karena asal-usulnya yang tidak jelas secara hukum. Lahan kebun yang berada di dalam kawasan hutan, tanah negara, dan areal Hak Guna Usaha (HGU) tidak bisa memiliki bukti kepemilikan tanah yang sah. Tanah dengan klaim yang tumpang tindih dipandang tanah bermasalah yang harus dikeluarkan dari ISPO. Hasil penelitian menunjukan bahwa perkebunan kelapa sawit swadaya dikembangkan di dua tipe status legal tanah yang ada di pedesaan.

Status pertama adalah perkebunan kelapa sawit yang dikembangkan di Kawasan Budidaya Non Kehutanan (KBNK) atau Area Penggunaan Lain (APL). Pada status pertama ini, penanaman kelapa sawit dinyatakan sah 
secara undang-undang kehutanan dan karenanya sesuai dengan prinsip-prinsip keberlanjutan dalam praktik perkebunan.

Status kedua adalah perkebunan kelapa sawit yang dikembangkan di Kawasan Budidaya Kehutanan (KBK). Kelapa sawit yang ditanam di atas lahan degan status seperti ini dinyatakan tidak sah secara undang-undang kehutanan dan tidak memenuhi prinsip-prinsip keberlanjutan dalam budidaya perkebunan. Pada lahan KBK inilah yang menjadi pokok persoalan penolakan produk sawit Indonesia ke negara negara Uni Eropa.

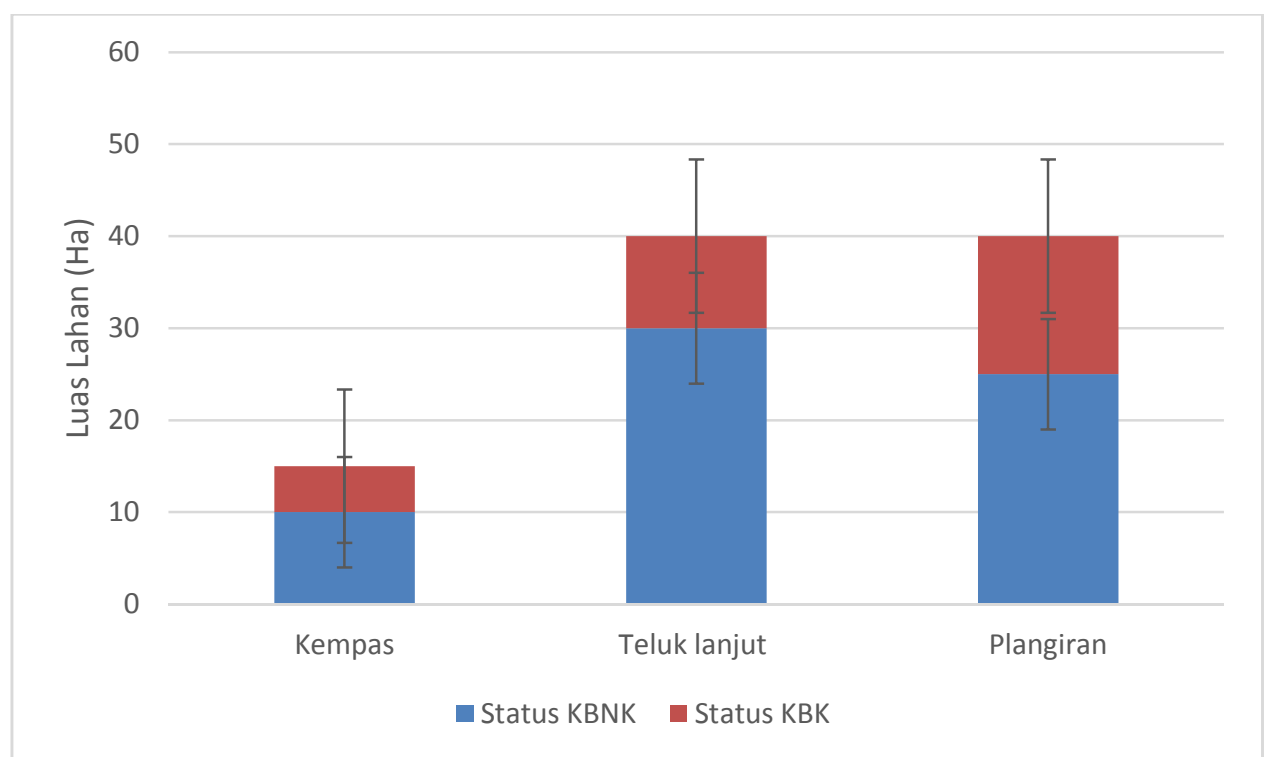

Gambar 3. Luas Penguasaan Rata-rata Rumah tangga Petani Kelapa Sawit Swadaya di Tiga Desa Penelitian, berdasarkan Letak/Status Legalnya, dalam Satuan Hektar (Ha)

Pada Gambar 3 diperlihatkan bahwa struktur agraria perkebunan kelapa sawit yang illegal (kelapa sawit di dalam Kawasan Budidaya Kehutanan/ KBK) di tiga desa sangat rendah dibandingkan perkebunan kelapa sawit di tanah yang legal (kelapa sawit di dalam Kawasan Budidaya Non Kehutanan/KBNK). Hal ini menunjukan bahwa petani swadaya di tiga desa tersebut tidak mempunyai masalah dalam legalitas dan status lahan budidaya. Fakta ini menunjukkan juga konsekuensi bahwa semua produksi kelapa sawit yang berasal dari tiga desa tersebut tidak beresiko terhadap konflik agraria, pemburukan kualitas lingkungan hidup dan ketidak berlanjutan sehingga dapat disertifikasi oleh ISPO.
Status illegal land biasanya disebabkan karena perkebunan kelapa sawit yang diusahakan berada di kawasan konservasi (forest conservation land) atau kawasan hutan produksi. Status illegal land biasanya berkaitan dengan pola ekspansi perkebunan kelapa sawit yang dilakukan oleh petani kelapa sawit swadaya karena tidak tersedianya lagi lahan di kawasan APL/KBNK yang tersisa.

Legalitas lahan juga ditunjukkan melalui kepemilikan sertifikat tanah. Studi Brandi et al. 2013 menunjukkan bahwa teridentifikasi bahwa terdapat gap antara persyaratan standar sertifikasi RSPO dengan praktik di lapangan, salah satunya adalah keberadaan sertifikat tanah yang sulit diadakan oleh petani. 
Fakta lapangan pada studi ini juga menunjukkan bahwa sertifikat tanah sebagai salah satu syarat dalam sertifikasi ISPO sepenuhnya belum terpenuhi. Sebagian besar petani kelapa sawti swadaya di tiga lokasi studi tidak memiliki sertifikat tanah melainkan hanya sebatas Surat Keterangan Tanah (SKT) atau Surat Keterangan Ganti Rugi (SKGR) yang dikeluarkan oleh badan berwenang pada level kecamatan dan desa. Baik SKT maupun SKGR bukan alas hakatas penguasaan lahan yang kuat dan sah di mata hukum formal.

\section{Kejelasan Sumber Bibit Kelapa Sawit}

Selain legalitas lahan, salah satu prinsip atau kriteria ISPO lainnya adalah tentang legalitas bibit yang ditandai dengan bibit kelapa sawit bersertifikat. Fakta di lapangan menunjukkan bahwa rumah tangga petani kelapa sawit swadaya membeli bibit kelapa sawit yang tidak bersertifikat. Asal usul bibit kelapa sawit yang ditanam adalah dari petani sawit lainnya yang bibitnya belum jelas legalitasnya, atau bibit kelapa sawit yang mereka gunakan adalah hasil pembibitan secara mandiri oleh para petani itu sendiri.

Hal ini dinilai sebagai bibit yang tidak sah, karena boleh jadi ada resiko atas penggunaan plasma nutfah yang tidak dapat dipertanggung jawabkan dampaknya di kemudian hari. Asal usul atau sumber kelapa sawit adalah hal yang sulit dilakukan bahkan dengan konsentrasi tinggi dalam produksi sawit dunia di Indonesia dan Malaysia (Dauvergne 2013). Pada tiga lokasi studi yang diteliti telah mewakili karakteristik petani kelapa sawit swadaya di Indonesia dalam memanfaatkan bibit di kebunnya. Karakteristik tersebut adalah bahwa persentase penggunaan bibit kelapa sawit bersertifikat biasanya tidak lebih dari $35 \%$ dari luas kawasan kebun kelapa sawit yang ada. Artinya sebagian besar kebun kelapa sawit yang ada tidak menggunakan bibit bersertifikat, walaupun dalam beberapa kasus di dalam satu persil kebun kelapa sawit terdapat pohon sawit yang sebagian bersertifikat dan sebagian lainnya tidak bersertifikat. Dari perspektif penggunaan bibit, dapat dikatakan bahwa sebagian besar lahan kebun petani kelapa sawit swadaya atau smallholders tidak memenuhi syarat ISPO.

Salah satu hal penting dalam sertifikasi ISPO adalah prinsip legalitas bibit atau bibit kelapa sawit bersertifikat untuk memenuhi standar tata kelolalingkungan hidup dan sumberdaya alam yang lestari. Bila prinsip legalitas bibit ini tidak terpenuhi, maka keseluruhan prinsip tidak berlaku bagi petani yang bersangkutan. Artinya setiap persil kebun yang di dalamnya tumbuh pohon kelapa sawit dengan bibit tidak bersertifikat, maka kebun tersebut dianggapillegal dari perspektif budidaya perkebunan yang berkelanjutan (ISPO). 


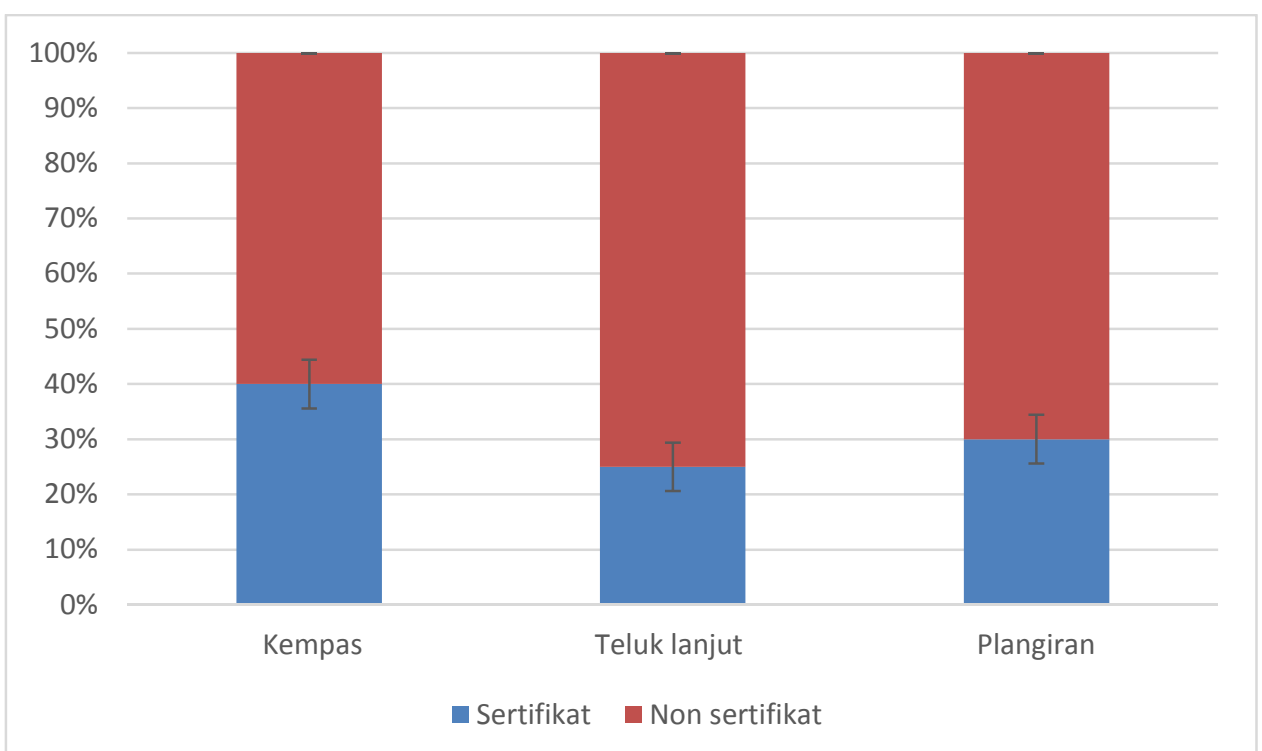

Gambar 5. Status Legalitas Bibit Kelapa Sawit di Tiga Desa dalam presentase

Melihat pada fakta bahwa di tiga lokasi studi tersebut menampilkan bibit kelapa sawit tanpa sertifikat yang dominan, maka dapat disimpulkan bahwa: a) sebagian besar petani kelapa sawit swadaya dapat dikatakan sebagai tidak taat pada prinsip tata kelola kelapa sawit yang berkelanjutan; b) oleh karena itu, petani sawit swadaya tersebut tidak akan bisa mengimplementasikan sertifikasi ISPO. Ujung dari persoalan ini sama, yaitu setiap produk yang dihasilkan oleh kebun kelapa sawit dari tanaman yang bibitnya dipandang illegal, maka akan ditolak oleh pasar internasional.

\section{PENUTUP}

Kesiapan petani kelapa sawit swadaya di tiga lokasi penelitian dalam menghadapi implementasi ISPO, secara struktur nafkah dinyatakan belum siap karena pendapatan dari oil palm bukan merupakan sumber nafkah yang utama atau dominan. Sisi legalitas lahan petani swadaya siap karena kebanyakan kebun budidaya kelapa sawit, meskipun sebagian besar lahan belum mempunyai sertfikat tetapi sudah surat ganti rugi dari camat. Sisi legalitas bibit juga dinyatakan tidak siap untuk mengimplementasikan ISPO karena sebagian besar petani kelapa sawit swadaya menggunakan bibit yang tidak jelas asal-usulnya.

\section{ACKNOWLEDGEMENT}

Petani swadaya ketiga desa, DPD APKASINDO INHIL dan semua pihak yang telah membantu terlaksananya penelitian ini.

\section{DAFTAR PUSTAKA}

Anonim. 2019. "Rancangan Per in Presiden Republik Indonesia Nomor 44 Tahun 2020 Tentang Sistem Sertifikasi Perkebunan Kelapa Sawit Berkelanjutan Indonesia." Perundang Undangan 4: 1-22.

Anwar, Rusli et al. 2016. "Pencapaian Standar Indonesian Sustainable Palm Oil (ISPO) Dalam Pengelolaan Perkebunan Kelapa Sawit Di Kalimantan Timur" Jurnal Penelitian Tanaman Industri 22(1): 11.

Apriyanto Mulono, Sutardi, Supriyadi, and Eni Harmayani. 2017. "Fermentasi Biji Kakao Kering 
Menggunakan

Saccharomycescerevisiae

Lactobacillus Lactis , Acetobacter Aceti." AGRITECH 37(3): 30211.

Apriyanto, Mulono, Sutardi Sutardi, Supriyanto Supriyanto, and Eni Harmayani. 2017. "Amino Acid Analysis of Cocoa Fermented by High Performance Liquid Chromatography (HPLC)." Asian Journal of Dairy and Food Research.

Brandi, Clara et al. 2013. Sustainability Certification in the Indonesian Palm Oil Sector: Benefits and Challenges for Smallholders.

Dauvergne, Peter. 2013. "Studying Global Environmental Meetings." Global Environmental Politics 13(August): 46-64.

Dharmawan, Arya Hadi et al. 2019. "Kesiapan Petani Kelapa Sawit Swadaya Dalam Implementasi ISPO: Persoalan Lingkungan Hidup, Legalitas Dan Keberlanjutan." Jurnal Ilmu Lingkungan 17(2): 304.

Euler, Michael et al. 2017. "Oil Palm Adoption, Household Welfare, and Nutrition Among Smallholder Farmers in Indonesia." World Development 93(January): 21935.

Gatto, Marcel, Meike Wollni, and Matin Qaim. 2015. "Oil Palm Boom and Land-Use Dynamics in Indonesia: The Role of Policies and Socioeconomic Factors." Land Use Policy 46: 292-303. http://dx.doi.org/10.1016/j.landuse pol.2015.03.001.

Hansen, Sune Balle et al. 2015. "Trends in Global Palm Oil Sustainability Research." Journal of Cleaner Production 100: 140-49. http://dx.doi.org/10.1016/j.jclepro. 2015.03.051.

Irianto dan Mulono Apriyanto. 2012. "Analisa Mutu Minyak Kelapa Sawit Mentah Di POM IV Nyato PT. TH INDO PLANTATIONS Kecamatan Pelangiran Kabupaten Indragiri Hilir Riau." Jurnal Teknologi Pertanian 1(2).

Mulyo, Jangkung Handoyo, Sugiyarto, and Arif Wahyu Widada. 2015. "Ketahanan Dan Kemandirian Pangan Rumah Tangga Tani Daerah Marginal DiKabupaten Bojonegoro." Agro Ekonomi 26(2): 121-28. https://jurnal.ugm.ac.id/jae/article/ view/17265/11256.

Nugraheni, Endang, and Nurmala Pangaribuan. 2008. "Pengelolaan Lahan Pertanian Gambut Secara Berkelanjutan." Universitas Terbuka, Tangerang Selatan Universitas Pajajaran: 73-88.

Puspa, Nandari. 2018. "Dinamika Kesiapan Petani Kelapa Sawit Dalam Penerapan Indonesia Sustainable Palm Oil (Ispo) Di Provinsi Jambi Nandari Puspa." Tesis, Departemen Manajemen Fakultas Ekonomi dan Manajemen Institut Pertanian Bogor.

Risa, Nisfi. 2018. "Perkebunan Kelapa Sawit di Provinsi Riau dalam Perspektif Pembangunan Berkelanjutan." https://www.researchgate.net/publi cation/325312286 Perkebunan (May).

Schouten, Greetje, and Pieter Glasbergen. 2011. "Creating Legitimacy in Global Private Governance." Ecological Economics 70(11): 1891-99. http://gateway.webofknowledge.co $\mathrm{m} /$ gateway/Gateway.cgi?GWVersi on $=2 \&$ SrcAuth $=$ SwissAcademicS 
oftware $\&$ SrcApp $=$ Citavi\&DestLin kType $=$ FullRecord $\&$ DestApp $=W$ OS\&KeyUT $=000298266200010$.

Sibarani, Dewi Yosefin Tumiar, Sakti Hutabarat, and Novia Dewi. 2015. "Prospek Dan Tantangan Petani Kelapa Sawit Swadaya Di Desa Air Hitam Kecamatan Ukui Kabupaten Pelalawan Dalam Menghadapi Sertifikasi ISPO." Jom Faperta 2(1): 1-9.

Takrama, J F et al. 2015. "Optimization of Cocoa Pulp Juice Fermentation with Yeast Starter Cultures of Cocoa Heap Fermentations." Journal of Agricultural Science and Food Technology 1(3): 22-33.

Wicke, Birka, Richard Sikkema, Veronika Dornburg, and André Faaij. 2011. "Exploring Land Use Changes and the Role of Palm Oil Production in Indonesia and Malaysia." Land Use Policy 28(1): 193-206.

http://dx.doi.org/10.1016/j.landuse pol.2010.06.001. 